RESEARCH ARTICLE

\title{
The Effect of Prostaglandin Analogues on Central Corneal Thickness
}

\author{
Umut Duygu Uzunel* \\ Private Doctor, Izmir, Turkey
}

*Corresponding author: Umut Duygu Uzunel, Private Doctor, Inonu Mh 6732/3 Sk No 3D Karsiyaka-Izmir, Turkey, Gsm: 0090-505-2656223,E-mail: druzunel78@yahoo.com

\begin{abstract}
Purpose: To evaluate the long-term effect of prostaglandin analogues on Central Corneal Thickness (CCT) in patients with glaucoma.

Materials and methods: This retrospective study included 73 eyes of 73 glaucoma patients and 75 eyes of 75 individuals with glaucoma suspect (control group). Newly diagnosed glaucoma patients with no previous glaucoma treatment were administered latanoprost $0.005 \%(n=27)$ or bimatoprost $0.03 \%$ $(n=24)$ or travoprost $0.004 \%(n=22)$ monotherapy once a day. CCTs were measured by ultrasound pachymetry before treatment and followed up annually for 5 years.

Results: A significant reduction in mean CCT was observed in the glaucoma group $(552.9 \pm 33.7 \mu \mathrm{m}$ vs. $523.6 \pm 31.4 \mu \mathrm{m}$, $\mathrm{p}<0.001)$, but not in the control group $(550.2 \pm 28.2 \mu \mathrm{m}$ vs. $550.1 \pm 28.2 \mu \mathrm{m}, p=0.276$ ) at 5-year follow-up. We observed a decrease in CCT $4.7 \mu \mathrm{m}$ in latanoprost group, $6.7 \mu \mathrm{m}$ in bimatoprost group and $6.4 \mu \mathrm{m} /$ per year in travoprost group. Both baseline and final CCT were positively correlated with the baseline and final IOP in glaucoma group $(r=0.243, p=0.039$; $r=0.334, p=0.004$, respectively).

Conclusions: PG analogues significantly reduced CCT in glaucoma patients after 5 years of treatment. In clinical practice, corneal thinning after topical PG analogues treatment could result in underestimation of IOP levels as measured by GAT.
\end{abstract}

\section{Keywords}

Latanoprost, Bimatoprost, Travoprost, Central corneal thickness, Glaucoma

\section{Introduction}

Prostaglandin (PG) analogues are being widely used to reduce Intraocular Pressure (IOP) in glaucoma patients. These drugs reduce IOP by stimulation of aqueous humor drainage primarily through the uveoscleral outflow pathway but significant effects on trabecular outflow facility also have been reported [1]. The sug- gested mechanism of IOP reduction involves aqueous humor outflow enhancement through the uveoscleral pathway accompanied by collagen degradation in the ciliary body. This collagen degradation is believed to be mediated by Matrix Metalloproteinases (MMPs) induced by prostaglandin F2-alpha [2,3]. Furthermore, because the cornea is mainly composed of collagen fiber [4], corneal thinning may be anticipated after prostaglandin treatment [1].

Elevated IOP is a risk factor for glaucoma and it's believed that to decrease the IOP values is the first choice of treatment in glaucoma [5]. Goldmann Applanation Tonometry (GAT) is known to be a standart method for IOP measurements however it's also well known that changes in Central Corneal Thickness (CCT) measurements may influence the GAT results accurate results of GAT are produced with a CCT of $520 \mathrm{~mm}$, but CCT values higher or lower than $520 \mathrm{~mm}$ produces unreliable IOP measurements by over or under estimating of IOP values [6]. Besides its importance in IOP measurements it's also been suggested that CCT is an independent risk factor of progression in open angle glaucoma [7].

The purpose of this study was to evaluate 5-year changes in the CCT in glaucoma patients treated with $\mathrm{PG}$ analogues monotherapy and to investigate the association between the CCT and the IOP in these patients.

\section{Material and Methods}

Medical charts of 3696 glaucoma patients who have been followed up at Izmir Bozyaka Training and Research Hospital were reviewed retrospectively. Seventy-three eyes of 73 glaucoma patients constituted the glaucoma group and 75 eyes of 75 glaucoma-suspect patients constituted the control group. The inclusion

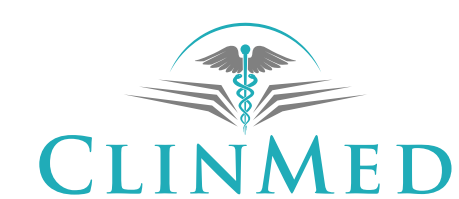

INTERNATIONAL LIBRARY
Citation: Uzunel UD (2018) The Effect of Prostaglandin Analogues on Central Corneal Thickness. Int J Ophthalmol Clin Res 5:084. doi.org/10.23937/2378-346X/1410084

Received: July 31, 2017: Accepted: March 29, 2018: Published: March 31, 2018

Copyright: () 2018 Uzunel UD. This is an open-access article distributed under the terms of the Creative Commons Attribution License, which permits unrestricted use, distribution, and reproduction in any medium, provided the original author and source are credited. 
criteria for the glaucoma group were newly diagnosed glaucoma patients (ocular hypertension and primary open angle glaucoma) treated with latanoprost $0.005 \%$ (Xalatan, Pharmacia Corp, Peapack, NJ) (Twenty-seven eyes of 27 patients) or bimatoprost $0.03 \%$ (Lumigan, Allergan, Irvine, CA) (Twenty-four eyes of 24 patients) or travoprost $0.004 \%$ (Travatan, Alcon Laboratories, Fort Worth, TX) (Twenty-two eyes of 22 patients) monotherapy for 5 years without change in regimen. All patients were compliant to the regular daily administration of the topical PG medication. Patients with the history of any previous intraocular surgery or laser treatment, retinal vascular or macular diseases, inflammatory diseases such as uveitis, current usage of steroid or non-steroidal anti-inflammatory medications were excluded. And also, patients who have any corneal disease and break-up time under 10 seconds wasn't taken to this study in order to increase the reliability of IOP measurements, and all measurements were performed by the same, well-trained examiner. All procedures conformed to the Declaration of Helsinki.

Best Corrected Visual Acuity (BCVA), IOP values measured by GAT, CCT by ultrasonic pachymeter PacScan 300p (Sonomed Inc., USA), slit-lamp biomicroscopy of anterior segment and fundus examination with 90 diopter lens findings were recorded from the medical charts of patients. For CCT measurements, the means of 5 consecutive readings were recorded. One eye of each patient was randomly selected for statistical analysis and the means of 5 consecutive measurements were considered for analysis. The CCT and IOP measurements before treatment and after 1, 2, 3, 4, and 5 years of treatment were analyzed.
Standard automated perimetry was performed twice with Humphrey Visual Field Analyzer (Carl Zeiss Meditec, Dublin, Ireland) by 30-2 Swedish Interactive Threshold Algorithytm (SITA) standard program. Only results with fixation loss $\leq 20 \%$, false negative and false positive ratio $\leq 15 \%$ in both tests were accepted as reliable. Mean Deviation (MD) and Pattern Standard Deviation (PSD) values were recorded.

The paired $t$-test, independent-samples $t$-test, chisquared test, repeated measures ANOVA and Pearson correlation analysis (running in SPSS version 21.0) were used for statistical analysis; a p-value $<0.05$ was considered statistically significant. The PostHoc analysis (with Bonferroni correction) was used for multiple comparisons.

\section{Results}

Demographic features at baseline are summarized in Table 1. There were no significant differences between these 2 groups with respect to age, sex, CCT, MD and PSD. Baseline IOP in the glaucoma group were significantly higher than the control group because of the higher IOP measurements prior to the medication ( $p<$ 0.001 , independent sample test).

No significant CCT change from baseline was observed in the control group after 5-year follow-up ( $p=$ 0.276 , repeated measure test). On the other hand, the change in the glaucoma group was statistically significant $(p<0.001$, repeated measure test). It was seen that the first year measurement of CCT was not statistically different from the baseline values, but the change at the $2,3,4$ and $5^{\text {th }}$ year measurements were statistically significant between the two groups (Table 2 and Figure 1 ).

Table 1: Demographic features at baseline.

\begin{tabular}{|l|l|l|l|}
\hline & Control group & Glaucoma group & p value \\
\hline Sex (Female/Male) & $(\mathbf{n = 7 5 )}$ & $\mathbf{( n = 7 3 )}$ & $0.642^{*}$ \\
\hline Age \pm SD (year) & $52: 23: 00$ & $48: 25: 00$ & $0.126^{* *}$ \\
\hline Mean CCT \pm SD (um) & $65.4 \pm 7.8$ & $67.3 \pm 7.4$ & $0.593^{* *}$ \\
\hline Mean IOP \pm SD (mmHg) & $550.2 \pm 28.2$ & $552.9 \pm 33.7$ & $<0.001^{* *}$ \\
\hline Mean MD \pm SD (dB) & $18.6 \pm 3.2$ & $21.7 \pm 3.4$ & $0.763^{* *}$ \\
\hline Mean PSD \pm SD (dB) & $-0.17 \pm 1.51$ & $-0.19 \pm 1.79$ & $0.748^{* *}$ \\
\hline
\end{tabular}

"Chi-square test; " Independent sample test.

SD: Standard Deviation; IOP: Intraocular Pressure; CCT: Central Corneal Thickness; MD: Mean Deviation; PSD: Pattern Standard Deviation.

Table 2: The comparison of annually changes in mean CCT between groups.

\begin{tabular}{|c|c|c|c|}
\hline & Control group $(n=75)$ & Glaucoma group $(n=73)$ & p value ${ }^{*}$ \\
\hline Baseline mean CCT \pm SD (ym) & $550.2 \pm 28.2$ & $552.9 \pm 33.7$ & 0.593 \\
\hline $1^{\text {st }}$ year mean $C C T \pm S D(4 m)$ & $549.9 \pm 28.2$ & $540.7 \pm 32.5$ & 0.064 \\
\hline $2^{\text {nd }}$ year mean $C C T \pm S D(4 m)$ & $550.1 \pm 28.0$ & $533.8 \pm 31.8$ & 0.001 \\
\hline $3^{\text {rd }}$ year mean $C C T \pm S D(4 m)$ & $549.9 \pm 28.1$ & $530.8 \pm 31.4$ & $<0.001$ \\
\hline $4^{\text {th }}$ year mean $C C T \pm S D(4 m)$ & $550.0 \pm 28.1$ & $526.4 \pm 33.2$ & $<0.001$ \\
\hline $5^{\text {th }}$ year mean CCT \pm SD $(4 \mathrm{~m})$ & $550.1 \pm 28.2$ & $523.6 \pm 31.4$ & $<0.001$ \\
\hline p value ${ }^{* *}$ & 0.276 & $<0.001$ & \\
\hline
\end{tabular}

*Independent sample test; ** Repeated measure test.

SD: Standard Deviation; CCT: Central Corneal Thickness. 


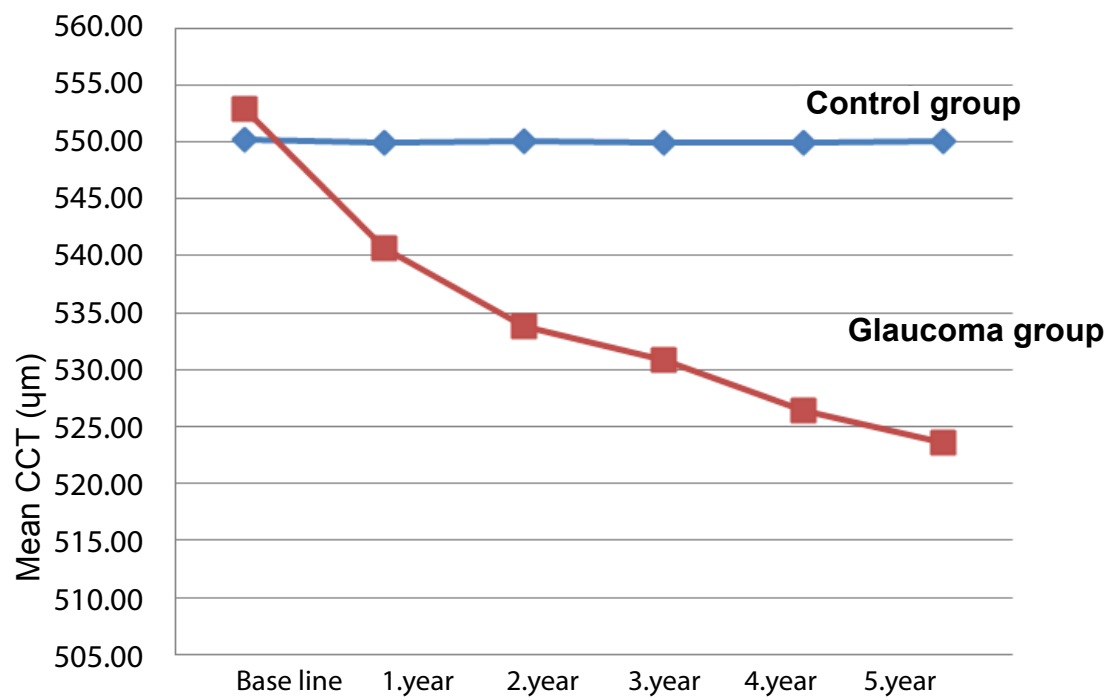

Figure 1: The annual changes in central corneal thickness (CCT) of groups.

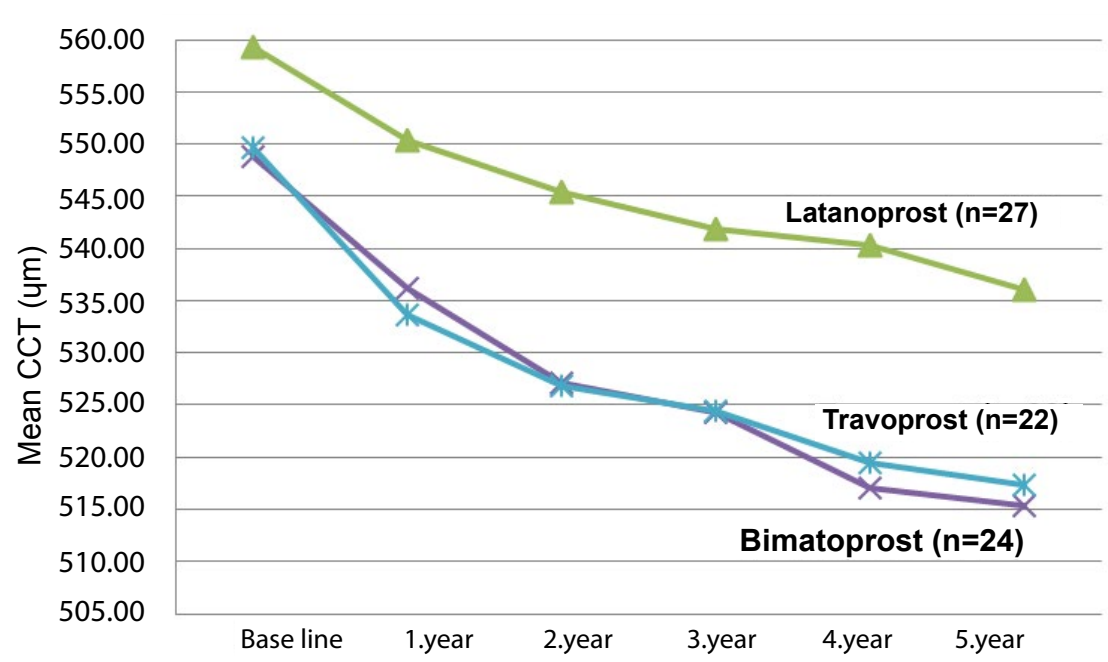

Figure 2: The annual changes in central corneal thickness (CCT) with PG analogues.

Table 3: The comparison of annually changes in mean CCT among PG analogs.

\begin{tabular}{|c|c|c|c|c|}
\hline & $\begin{array}{l}\text { Latanoprost } \\
\text { (n = 27) }\end{array}$ & $\begin{array}{l}\text { Bimatoprost } \\
(n=24)\end{array}$ & $\begin{array}{l}\text { Travoprost } \\
\text { (n= 22) }\end{array}$ & p value ${ }^{*}$ \\
\hline Age \pm SD (year) & $65.5 \pm 9.2$ & $68.5 \pm 7.1$ & $68.1 \pm 4.3$ & 0.289 \\
\hline Baseline mean CCT \pm SD (ym) & $559.3 \pm 35.9$ & $548.8 \pm 36.1$ & $549.6 \pm 28.0$ & 0.471 \\
\hline $1^{\text {st }}$ year mean CCT $\pm S D(4 m)$ & $550.4 \pm 34.4$ & $536.2 \pm 30.8$ & $533.6 \pm 30.2$ & 0.142 \\
\hline $2^{\text {nd }}$ year mean $C C T \pm S D(4 m)$ & $545.4 \pm 33.9$ & $527.1 \pm 32.9$ & $526.9 \pm 24.5$ & 0.058 \\
\hline $3^{\text {rd }}$ year mean $C C T \pm S D(4 m)$ & $541.8 \pm 31.0$ & $524.3 \pm 33.9$ & $524.4 \pm 26.1$ & 0.058 \\
\hline $4^{\text {th }}$ year mean CCT \pm SD (um) & $540.3 \pm 32.5$ & $517.1 \pm 29.3$ & $519.4 \pm 29.5$ & 0.020 \\
\hline $5^{\text {th }}$ year mean CCT $\pm S D(4 m)$ & $536.0 \pm 32.5$ & $515.3 \pm 30.3$ & $517.4 \pm 27.3$ & 0.032 \\
\hline$\triangle \mathrm{CCT}$ (чm) & $23.3 \pm 14.5$ & $33.4 \pm 14.6$ & $32.2 \pm 10.2$ & 0.016 \\
\hline$p$ value ${ }^{* *}$ & $<0.001$ & $<0.001$ & $<0.001$ & \\
\hline
\end{tabular}

"ANOVA test; "*Repeated measure test.

SD: Standard Deviation; CCT: Central Corneal Thickness; $\Delta$ : Change of value from baseline.

The comparison of annually changes in mean CCT among PG analogs was seen in Table 3 and Figure 2. No significant difference was found in CCT changes at the $1^{\text {st }}, 2^{\text {nd }}$ and $3^{\text {rd }}$ year, but there was statistically significant difference in CCT changes at the $4^{\text {th }}$ and $5^{\text {th }}$ year and it was related to the differences between the latanoprost and bimatoprost groups ( $p=0.030$ for $4^{\text {th }}$ year, $p=0.046$ for $5^{\text {th }}$ PostHoc analysis with Bonferroni correction). It was seen that the decrease in mean CCT was $4.7 \mu \mathrm{m}$ in latanoprost group, $6.7 \mu \mathrm{m}$ in bimatoprost group and $6.4 \mu \mathrm{m} /$ per year travoprost group. The reduction in CCT was statistically significant different among PG analogs and it was related to the difference of the effects of bimatoprost and latanoprost on CCT ( $p=0.026$, PostHoc analysis with Bonferroni correction). 


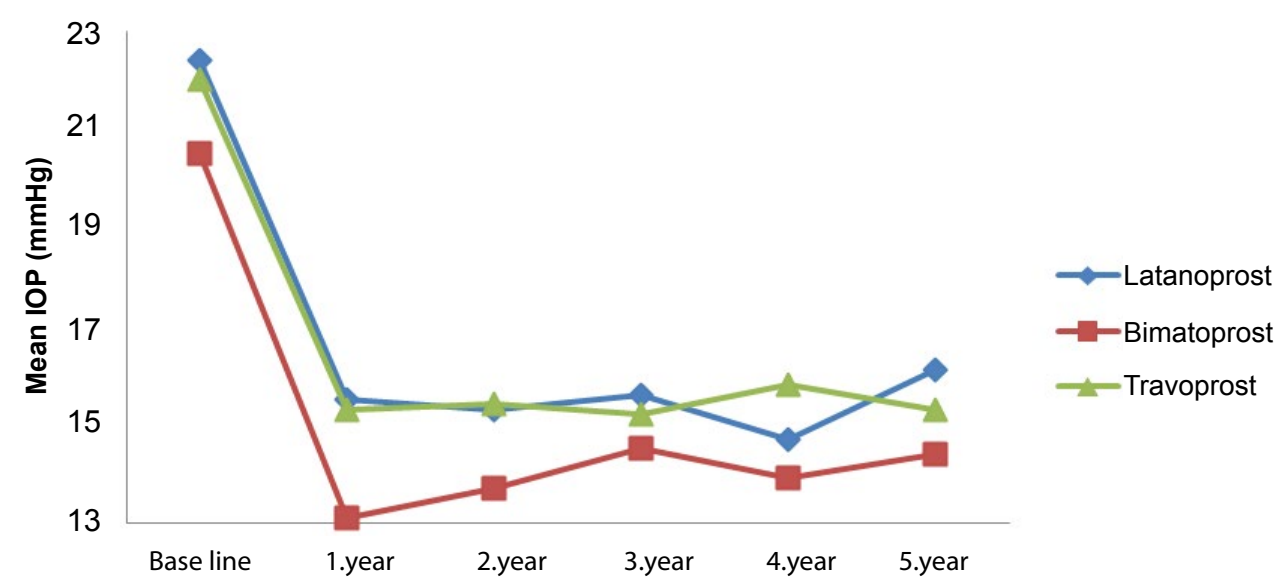

Figure 3: The annual changes in intraocular pressure with $P G$ analogues.

Table 4: Correlations between IOP and CCT values at baseline and during follow-up.

\begin{tabular}{|c|c|c|c|c|}
\hline & \multicolumn{2}{|c|}{ Control group $(n=75)$} & \multicolumn{2}{|c|}{ Glaucoma group $(\mathrm{n}=73$} \\
\hline & $\mathbf{r}^{*}$ & $\mathbf{p}$ & $\mathbf{r}^{*}$ & p \\
\hline Baseline mean CCT vs. baseline mean IOP & 0.185 & 0.111 & 0.243 & 0.039 \\
\hline Final mean CCT vs. final mean IOP & 0.163 & 0.162 & 0.334 & 0.004 \\
\hline$\triangle C C T$ vs. $\triangle$ IOP & -0.039 & 0.740 & 0.078 & 0.514 \\
\hline
\end{tabular}

'Pearson's correlation coefficient.

IOP: Intraocular Pressure; CCT: Central Corneal Thickness; $\Delta$ : Change of value from baseline.

No significant IOP change from baseline was observed in the control group after 5-year follow-up (17.9 $\pm 2.9 \mathrm{mmHg}$ vs. $17.7 \pm 3.1 \mathrm{mmHg}, p=0.587$ ); on the other hand, statistically significant difference was observed in the glaucoma group $(21.7 \pm 3.3 \mathrm{mmHg}$ vs. 15.3 $\pm 2.9 \mathrm{mmHg}, p<0.001)$. All of the three PG analogs lowered the IOP effectively $(22.4 \pm 3.1 \mathrm{mmHg}$ vs. $16.1 \pm 3.0$ $\mathrm{mmHg}, \mathrm{p}=0.000$ for latanoprost; $20.5 \pm 3.7 \mathrm{mmHg}$ vs. $14.4 \pm 2.3 \mathrm{mmHg}, \mathrm{p}<0.001$ for bimatoprost; $22.0 \pm 3.0$ $\mathrm{mmHg}$ vs. $15.3 \pm 3.3 \mathrm{mmHg}, \mathrm{p}<0.001$ for travoprost). The reduction of IOP was statistically higher in bimatoprost group than in latanoprost and travoprost group at the first-year follow-up $(p=0.002, p=0.010$, respectively, PostHoc analysis with Bonferroni correction). It was observed that the reduction of IOP from baseline was $28.1 \%$ in latanoprost group, $29.8 \%$ in bimatoprost group and $30.4 \%$ in travoprost group Figure 3.

Table 4 shows the relationship between CCT and IOP values at baseline and at the 5-year follow-up. Both baseline CCT was found to be positively correlated with baseline IOP and final CCT was found to be positively correlated with final IOP in glaucoma group $(r=0.243, p$ $=0.039 ; r=0.334, p=0.004$, respectively). No significant correlation was apparent between CCT and IOP values in the control group.

\section{Discussion}

Latanoprost and travoprost are pharmacologically classified as prostaglandin analogues, but bimatoprost is considered by some to be a prostamide because it is an amide rather than an ester compound [8]. However, these 3 drugs belong to the same family and have a similar action [9]. The IOP reduction obtained with pros- taglandin analogues may be related to the activation of MMPs. The cornea is mainly composed of collagen fibers; prostaglandin analogues seem to affect the corneal stromal structure by decreasing the extracellular matrices [10]. One of the mechanisms considered responsible is the biochemical change between the corneal fibroblasts by increasing matrix metalloproteinases MMP-1 and MMP and reducing different collagen types (I, II, IV, VI) [11]. It has been shown that cultured corneal fibroblasts have been induced to contract when exposed to latanoprost for three days and have not reacted when exposed to timolol maleate [12].

Most of the recent studies have showed that prostaglandin analogues could decrease the central corneal thickness (CCT) values [13-19]. Lee and Cho [13] observed that latanoprost significantly reduced CCT in normal-tension glaucoma patients after 5 years of treatment. Harasymowycz, et al. [14] showed that treatment with travoprost was associated with CCT thinning and CCT decreased $6.9 \mu \mathrm{m}$ in 6 weeks. Sen, et al. [15] observed a significant reduction in CCT at the $6^{\text {th }}, 12^{\text {th }}$, and $24^{\text {th }}$ months in 188 eyes of 94 patients under topical latanoprost and bimatoprost medications. Arcieri, et al. [16] found a statistically significant CCT reduction $(0.6 \%)$ in 34 glaucoma patients within the first month of bimatoprost treatment, but no change was observed in latanoprost and travoprost treatment groups. In 69 eyes, Zhong, et al. [17] determined that topical therapy with PGs is associated with CCT reduction and latanoprost, travoprost, and bimatoprost have a similar effect on CCT. In their 8-weeks study, Hatanaka, et al. [18] compared the influence of PGs and prostamide on CCT and found that topical therapy both PGs and bimato- 
prost is associated with CCT reduction. Viestenz, et al. [19] demonstrated a reduction of CCT in patients under treatment with topical prostaglandin F2-alpha, when compared with topical carbonic anhydrase inhibitors. In only 2 studies, PGs were found to increase the CCT value slightly $[9,11]$. In our study, we observed that all of the PG analogues significantly reduced CCT after 5-year of follow-up. We saw a decrease in CCT $4.7 \mu \mathrm{m}$ in latanoprost group, $6.7 \mu \mathrm{m}$ in bimatoprost group and 6.4 $\mu \mathrm{m} /$ per year in travoprost group and the CCT thinning was mainly found within the initial 1-year treatment period in the 3 prostaglandin analogues. CCT thinning seen in our study could be explained with the contraction of corneal stroma induced by PGs.

Ehlers, et al. [6] had found $5 \mathrm{mmHg}$ change in IOP for $70 \mu \mathrm{m}$ of CCT variation. Doughty and Zaman [20] in their metaanalysis, had reported the relationship as $2.5 \mathrm{mmHg}$ IOP change per $50 \mathrm{~mm}$ CCT variation. In our study, prostaglandin analogues decreased CCT values at around $30 \mu \mathrm{m}$ accounting for 2.14 and $1.50 \mathrm{mmHg}$ falsely lower IOP values according to Ehlers and Doughty IOP correction formulas, respectively. Similarly, we found both baseline and final CCT were positively correlated with the baseline and final IOP in glaucoma group.

In a metaanaliz study, the prostaglandins, as a class, demonstrated the greatest decrease in pressure from untreated baseline [21]. Among the 3 prostaglandins, bimatoprost (29\%) and travoprost (27\%) showed the greatest reduction compared with latanoprost (24\%). We observed that the reduction of IOP from baseline was $28.1 \%$ in latanoprost group, $29.8 \%$ in bimatoprost group and $30.4 \%$ in travoprost group.

There are some limitations to this study. In particular, it is limited by its retrospective design and by small patient numbers. We evaluated only the long-term effect of prostaglandin analogues on central corneal thickness (CCT) in patients with glaucoma. We could not assess whether the thinning of CCT has an effect on glaucoma progression, due to lack of data.

In summary, PG analogues significantly reduced CCT in glaucoma patients after 5 years of treatment. The effect of prostaglandin analogue drops on the corneal thickness and the potential impact on the measurement of the IOP should thus be carefully considered in the clinical setting, especially when these drugs are administered over an extended period of time.

\section{Financial Disclosure}

No financial support was received for this submission.

\section{Conflict of Interest}

None of the authors has conflict of interest with the submission.

\section{References}

1. Toris CB, Gabelt BT, Kaufman PL (2008) Update on the mechanism of action of topical prostaglandins for intraocular pressure reduction. Surv Ophthalmol 53: 107-120.

2. Schachtschabel U, Lindsey JD, Weinreb RN (2000) The mechanism of action of prostaglandins on uveoscleral outflow. Curr Opin Ophthalmol 11: 112-115.

3. Sagara T, Gaton DD, Lindsey JD, Gabelt BT, Kaufman PL, et al. (1999) Topical prostaglandin F2alpha treatment reduces collagen types I, III, and IV in the monkey uveoscleral outflow pathway. Arch Ophthalmol 117: 794-801.

4. BenEzra D, Foidart JM (1981) Collagens and non collagenous proteins in the human eye. I. Corneal stroma in vivo and keratocyte production in vitro. Curr Eye Res 1: 101110.

5. Goldmann H, Schmidt T (1957) [Applanation tonometry]. Ophthalmologica 134: 221-242.

6. Ehlers N, Bramsen T, Sperling S (1975) Applanation tonometry and central corneal thickness. Acta Ophthalmol (Copenh) 53: 34-43.

7. Herndon LW, Weizer JS, Stinnett SS (2004) Central corneal thickness as a risk factor for advanced glaucoma damage. Arch Ophthalmol 122: 17-21.

8. Lim KS, Nau CB, O'Byrne MM, Hodge DO, Toris CB, et al. (2008) Mechanism of Action of Bimatoprost, Latanoprost, and Travoprost in Healthy Subjects. A Crossover Study. Ophthalmology 115: 790-795.

9. Bafa M, Georgopoulos G, Mihas C, Stavrakas P, Papaconstantinou D, et al. (2009) The effect of prostaglandin analogues on central corneal thickness of patients with chronic open-angle glaucoma: a 2-year study on 129 eyes. Acta Ophthalmol 89: 448-451.

10. Wu KY, Wang HZ, Hong SJ (2005) Effect of latanoprost on cultured porcine stromal cells. Curr Eye Res 30: 871-879.

11. Tsikripis P, Papaconstantinou D, Koutsandrea C, Apostolopoulos M, Georgalas I (2013) The effect of prostaglandin analogs on the biomechanical properties and central thickness of the cornea of patients with open-angle glaucoma: a 3-year study on 108 eyes. Drug Des Devel Ther 7: 1149-1156.

12. Liu Y, Yanai R, Lu W, Hirano S, Sagara T, et al. (2006) Effects of antiglaucoma drugs on collagen gel contraction mediated by human corneal fibroblasts. J Glaucoma 15: 255-259.

13. Lee $\mathrm{H}$, Cho BJ (2015) Long-term effect of latanoprost on central corneal thickness in normal-tension glaucoma: Five -year follow-up results. J Ocul Pharmacol Ther 31: 152-155.

14. Harasymowycz PJ, Papamatheakis DG, Ennis M, Brady M, Gordon KD, et al. (2007) Relationship between travoprost and central corneal thickness in ocular hypertension and open-angle glaucoma. Cornea 26: 34-41.

15. Sen E, Nalcacioglu P, Yazici A, Aksakal FN, Altinok A, et al. (2008) Comparison of the effects of latanoprost and bimatoprost on central corneal thickness. J Glaucoma 17: 398-402.

16. Arcieri ES, Pierre Filho PTP, Wakamatsu TH, Costa VP (2008) The effects of prostaglandin analogues on the blood aqueous barrier and corneal thickness of phakic patients with primary open-angle glaucoma and ocular hypertension. Eye 22: 179-183.

17. Zhong Y, Shen X, Yu J, Tan H, Cheng Y (2011) The comparison of the effects of latanoprost, travoprost, and bimatoprost on central corneal thickness. Cornea 30: 861-864.

18. Hatanaka M, Vessani RM, Elias IR, Morita C, Susanna R Jr (2009) The effect of prostaglandin analogs and prostamide on central corneal thickness. J Ocular Pharmacol Ther 25: 51-53. 
19. Viestenz A, Martus $P$, Schlötzer-Schrehardt U, Langenbucher A, Mardin CY (2004) [Impact of prostaglandin-F(2alpha)-analogues and carbonic anhydrase inhibitors on central corneal thickness -- a cross-sectional study on 403 eyes]. Klin Monbl Augenheilkd 221: 753-756.

20. Doughty MJ, Zaman ML (2000) Human corneal thickness and its impact on intraocular pressure measures: a review and meta-analysis approach. Surv Ophthalmol 44: 367-408.

21. Stewart WC, Konstas AG, Nelson LA, Kruft B (2008) Meta-analysis of 24-hour intraocular pressure studies evaluating the efficacy of glaucoma medicines. Ophthalmology 115: $1117-1122$. 